the patient can submit no longer, and if the patches are local and large a piece of lint should be saturated with the tincture and tied on for several consecutive hours, even days, if necessary. The treatment must be persevered with until the whole of the morbid material is cast off; and when this occurs we shall find the true skin smooth and shining, looking like gutta-percha tissue, stained as it is with the tar. The misfortune is that this treatment is tedious and objectionable for both nurse and patient, and can only be carried out efficiently in a hospital or medical home, or at least with the assistance of a trained nurse. When the patient has sacrificed three or four weeks to this treatment the general result has been satisfactory, and some cases have, so far as I know, been conpletely cured; but I doubt whether any measures are capable of preventing a relapse. It is scarcely necessary to add that no claim is raised for originality in the application of soap, spirit, and tar in cases of psoriasis. Hebra, that king of dermatologists, was, so far as I know, the first to use the combination.

\section{A CASE ILLUSTRATING AN EARLY STAGE OF HERNIA OF THE BLADDER.}

BY FREDERICK TREVES, F.R.C.S. FNG,

SURGEON TO, AND LECTURER ON SURGERY AT, THE LONDON HOSPITAL.

THE comparative rarity of hernia of the bladder and the little knowledge possessed of the mode of formation of this rapture may excuse the publication of the following case.

A man aged thirty-one came under my care with a double inguinal hernia. He had lived a life of undisturbed leisure, was the reverse of energetic, and took little or no exercise. His whole muscular system was below the average in the matter of development, his tissues were very flabby, and although he was by no means corpulent he had been increasing in weight for some little time. The abdomen was lax and unduly pendulous for a man of his years, and the amount of subcutaneous fat in the parietes was large. He had noticed the hernix for about two years, the left rupture having appeared before the right. A well-fitting double inguinal truss had been worn for the last twelve months. The right hernia was the larger of the two. It formed a swelling which was about the size of a hen's egg as it projected beyond the inguinal ring. It had reached but a little way into the scrotum. It felt soft and was peculiarly rounded. The impulse on conghing was marked, and the protrusion was perfectly reducible. I noticed that while the hernia could be most readily replaced it appeared again the moment the fingers were taken away. The contents appeared to be omental. The ring readily admitted two fingers. The hernia on the left side was very like that on the right. The ring was about the same size, but the protrasion was much smaller. The patient complained of strange, indefinite pains about the lower part of the abdomen. He had no bladder trouble, and his chief complaint was of a constant sense of painful weakness in the groins. He had some pain, moreover, along the inner side of the right thigh. He was very anxious to have both herniæ treated by operation. He was much worried by wearing a truss, and expressed his intention of discontinuing the apparatus in any case. It was pointed out to bim that the ruptures coald be perfectly supported by a truss, and that an operation was not a necessity. He claimed, however, that the truss gave him so much inconvenience that he could not submit to the continued wearing of it. This persistent sense of discomfort in the groin, even when an admirable truss was being worn, was a very noticeable feature. I proceeded to carry out the operation for the radical cure. On exposing the external ring on the right side I found a soft, well-defined, and well-rounded protrasion behind the structures of the cord. It looked like an omental hernia in a very thin sac, but an examination showed that it was in reality a retroperitoneal fatty hernia. When I had removed the fat composing this reducible mass I found in its interior a peritoneal sac about one inch and a half in length as measured by the part drawn out beyond the external ring. This sac, which was quite empty, was ligatured and removed. The removal of this fatty hernia revealed another and larger fatty protrusion behind it. There seemed, indeed, to be two herniæ projecting from the inguinal canal, one behind the other, and in front of the anterior of the two was the cord. The removal of the fat from the second protrasion disclosed in its interior a strangeooking mass which was soon shown to be the bladder. The fat seemed to be adherent to it. When the fat was dragged upon the viscus was drawn out of the ring, while a very little pressure served to reduce it. When reduced I could readily pass a finger into the ante-vesical space. No serous membrane came into view. An examination of the muscular fibres of the exposed bladder made it apparent that the part protruded was the extreme summit. The extruded portion when dragged forward projected (or rather could be made to project) about two inches beyond the external ring. I removed as much fat as possible and closed the external ring with sutures. The hernia on the left side was also a fatty hernia which had come down behind the cord, and which likewise contained in its interior a small empty peritoneal sac. The patient's recovery was aneventful.

Remarks.-This case certainly gerves to illustrate the "traction" theory of hernia as held by some. There is an increase in the subperitoneal fat; it grows in a direction of little resistance-viz, along the inguinal canal-and drags a small pouch of peritoneum after it. In the same way the fat in the ante-vesical space extends along the inguinal canal and drags a portion of the bladder after it. Had the fatty hernia extended to the scrotum the hernia of the bladder would have been quite considerable, the protrusion would have been free of any sac, and the viscus would probably have become more or less irreducible. The case certainly shows the part a fatty hernia may play in producing a protrusion of the bladder.

Wimpole-street, $\mathrm{W}$

ON A

SEVERE FORM OF ULCERATIVE COLITIS OCCURRING IN YOUNG CHILDREN IN THE ARGENTINE.

BY GEORGE MACKERN, M.D. LOND.,

LATE VISITING PHYSICIAN TO THE BRITISH HOSPITAL, BUENOS AYRES.

As the subject of colitis seems to be attracting some attention just at present, and as an addendum to Dr. Hale White's article on "Colitis" which appeared in THE LANCET of March 2ad, I should like to describe a form of severe alceration of the lower bowel which I have observed as occurring in young children in Buenos Ayres, and which differs very much in its clinical aspects from the usual forms of colitis referred to in that article and in the various textbooks. The form I am about to describe must be carefully distinguished from the other and acute forms of intestinal disease which are commonly observed in semi-tropical climates. The Argentine Republic over its greater extent, and more especially the provine of Buenos Ayres, enjoys a semitropical or temperate climate, subject, however, to great and sudden changes in temperature. The hot months are January and February, with a mean temperature of $80^{\circ}$ to $85^{\circ} \mathrm{F}$, with occasional exacerbations to $90^{\circ}, 95^{\circ}$, or even $100^{\circ}$ in the shade, this excessive rise being usually accompanied by a soft north wind blowing from the extensive swamps of the Upper Parana and Matto Grosso districts of Southern Brazil. This north wind produces an extraordinarily depressing and nervous effect on both native and foreign residents. Lassitude, disinclination for bodily and mental exertion, and a peculiar irritability of temper are felt alike by all classes during the two or three days the wind lasts. On such days special precautions must be taken with regard to fresh foods, milk turning sour in a couple of hours, fresh meat beginning to decompose in three or four, while certain fruits rich in sugar will also ferment in a few hours. This great heat calminates in a storm of wind often accompanied by bail, and the temperature drops perhaps $25^{\circ}$ or $30^{\circ}$ in an hour's time. It is at such times as these that acute and fatal forms of diarrhoea may occur both in adults and in children, in the latter case chicfly due, no doubt, to the ingestion of milk rendered toxic under the influence of the microbe-bearing north wind. Children under two years of age succumb much more rapidly to this form of diarrboes than older children using a more mixed diet, and adults, though they suffer severely, seldom die from acute attacks. Clinical and pathological observations show that it is the upper part of the intestinal tract which chietly suffers, and there is often vomiting at the beginning of the attacks, which 